\title{
Building Faculty Community: Implementation of a Research Colloquium Series
}

\author{
Michelle Dennis \\ Adler University \\ Donna DiMatteo-Gibson \\ Adler University \\ James D. Halbert \\ Adler University \\ Marcelo Gonzalez \\ Adler University \\ Ingrid Prioleau Byrd \\ Adler University
}

This paper describes the development, implementation, and preliminary evaluation of a research colloquium series for adjunct faculty teaching in a doctoral program offered through the online campus of a midsized university. The study described here provides an analysis of the impact of participation in the newly developed colloquium series on faculty work engagement and related constructs. Focus groups were employed, to identify relevant themes pertaining to engagement. Findings are discussed in the context of Self-Determination Theory.

Keywords: self-determination theory, adjunct faculty, research colloquium series, faculty engagement

\section{INTRODUCTION}

This study explored the implementation and impact of a Research Colloquium Series offered to faculty teaching in a doctoral program offered through the online campus of a mid-sized university. Participation in the series was investigated in terms of its potential impact on levels of faculty engagement. Feedback obtained through a faculty focus group and aspects of the series, such as content and format, were evaluated in terms of Self-Determination Theory.

\section{Literature Review}

The construct of employee engagement has been described as an emotional commitment to an organization and its mission (Byrne, Peters \& Weston, 2016). Employee engagement in the field of higher 
education was explored in terms of its impact on faculty retention and job satisfaction (Hakeem \& Gulzar, 2015). Additionally, work engagement has been shown to impact performance among higher education faculty (Deligero \& Laguador, 2014). Communities of practice have also been shown to contribute to faculty engagement (Golden, 2016).

Research by Dolan (2011) described the potential for isolation in online faculty. Professional development can be utilized to create a sense of community among adjunct faculty (Surak \& Pope, 2016; Webb, Wong \& Hubball, 2013). Research indicated that faculty might choose not to engage in online communities due to workload and perceptions that engagement was not a part of their formal position (Khalid, Joyes, Ellison \& Daud, 2014). As engagement impacts student satisfaction, incorporating activities, which encourage faculty to feel connected to their institutions, was of paramount importance. Synchronous sessions have been shown to contribute to faculty engagement with students (Haung \& E.Ling, 2012; Kreie, Johnson \& Lebsock, 2017; Lowenthal, Snelson \& Dunlap, 2017; Park \& Bonk, 2007).

Mueller, Mandernach \& Sanderson (2013) reported that students working with full-time faculty reported higher levels of engagement. This may be due to the levels of engagement experienced by fulltime and adjunct faculty. Steps can be taken to increase engagement among adjunct faculty. Specifically, Benton \& Li (2015) looked at the role of the Department Chair in developing a sense of community among online adjunct faculty. Meixner, Kruck \& Madden (2010) described considerations for the inclusion of part-time faculty in departmental activities. Smith (2015) depicted challenges, which were often associated with mentoring faculty in a web-based learning environment due to a lack of physical proximity and recommended the incorporation of meaningful dialogue and relationship building, in concert with an emphasis on training and development.

The benefits of learning communities have been explored (Jackson, Stebleton \& Laanan (2013) and established as a strategy for developing authentic relationships with students and increased levels of engagement. Service-learning seminars for faculty have been shown to increase engagement (Borrero \& Reed, 2016). Additionally, online open courses for faculty development demonstrated a positive impact on faculty satisfaction (Moskal, Thompson \& Futch, 2015). Research by Loversidge \& Demb (2015) indicated that faculty tend to have positive perceptions of interprofessional education.

Renner (2017) reported that involving faculty in online research communities as an effective way to create engagement. Research by Vines (2010) described the potential impact of informal peer colloquia on engagement among law students. Van den Berg, Bakker \& Cate (2013) focused on key factors, which impact work engagement and job motivation among teaching faculty. These factors included teaching about one's specialty, noting appreciation for teaching from one's direct supervisor, teaching small groups, feedback on performance and freedom to determine content taught. These factors were shown to align with the basic needs articulated in Self-Determination Theory (Martinek, 2019).

Self-Determination theory (Ryan \& Deci, 2000) provides a framework from which to analyze motivation. Intrinsic motivation relates to factors internal to the individual, which serve to impact action. For instance, interest may serve as an intrinsic facet of motivation. External motivation refers to factors outside of the individual, which may impact action. For instance, rewards serve as external motivators. Self-Determination Theory posits that intrinsic motivation may be facilitated by social and cultural factors. Autonomy, competence and relatedness are all factors that impact action, thereby contributing to a level of performance, degree of persistence, and level of engagement (Deci \& Ryan, 2000).

With respect to faculty engagement, the theory of Self-Determination predicts that a sense of autonomy in the work environment may reduce perceptions of workload and stress and contribute to motivation. Additionally, faculty perceptions of the degree to which learning community initiatives are related to their interests and roles should impact outcomes (Beachboard, Beachboard, Li and Adkinson (2011). Jansen in de Wal, van den Beemt, Martens, \& den Brok (2020) found that there are longitudinal relationships among professional learning, teachers' experience of job resources, motivation, and need satisfaction. Stupnisky, BrckaLorenz, Yuhas, \& Guay (2018) found support for faculty autonomy, competence and intrinsic motivation. Autonomous motivation predicted more use of teaching strategies that were more focused on higher-order and collaborative learning opportunities for the students. 
Stupnisky, Hall, Daniels, \& Mensah (2017) also found support for self-determination theory. Faculty who engaged in teaching and research who had intrinsic motivation for these activities felt more success.

The current study was conducted in the online campus of a midsized university. One doctoral program offered through the campus was selected for the implementation and initial evaluation. This program employs 16 adjunct faculty members. Engaging adjunct faculty members is of paramount importance in online doctoral programs, given the necessary emphasis on research and student mentorship. The development of the Research Colloquium Series Model (see Appendix A) was precipitated by administrator needs regarding the engagement of geographically distributed faculty. A related goal of the series was to provide doctoral students with the opportunity to learn about the research of the faculty and to build relationships with potential dissertation chairpersons.

The Research Colloquium Series provided faculty teaching for the program with the opportunity to present planned, ongoing and/or complete research projects in which they were involved during synchronous program-wide meetings. Additionally, faculty were able to present on topics proposed by doctoral students with relevance to the research process. Faculty and doctoral students came together outside of the online course room and met via the Zoom web conferencing system. Meetings were scheduled once per semester and the duration of each meeting was one hour. The series had the following aims:

1. Engage faculty and students outside of the online course room in meaningful ways, thereby contributing to the development of community.

2. Maximize meaningful interactions in a synchronous environment, thereby contributing to student and faculty engagement.

3. Provide faculty and students with a forum to discuss research.

4. Provide faculty with opportunities to mentor students throughout the research process.

The first meeting was conducted in September of 2018, and focused on investigating leadership, diversity and inclusion. Session two of the series was presented in April of 2019 and focused on key steps in the research process. Session three was presented in September of 2019 and focused on the development of research topics. The current study investigated faculty perceptions of the impact and utility of the Research Colloquium Series described above through the use of a focus group. Questions for the focus group centered around the constructs of engagement, community, and satisfaction.

\section{METHOD}

In this study, a preliminary focus group was conducted to evaluate faculty perceptions regarding the impact of the colloquium series. Participants included eleven doctoral faculty members teaching for the online campus of a midsized university. Faculty were recruited via an announcement sent by program administration inviting input regarding the Research Colloquium Series.

Questions were selected for inclusion in the focus group based on literature emphasizing the constructs of community, satisfaction, and engagement. Henrie, Halverson \& Graham (2015) evaluated the mediation of learning experiences by technology in a review of the literature on scales which assess behavioral, cognitive, and emotional indicators of engagement. Bolliger \& Wasilik, (2009) reported that student, instructor, and institution factors contribute to faculty satisfaction. Student factors demonstrated the highest potential to generate satisfaction among faculty, while institutional factors, such as workload allocation and technology issues, contributed most strongly to faculty dissatisfaction. Six questions were posed to the faculty in attendance:

1. Does the series build an academic community in online courses?

2. Does the series impact student perceptions of faculty presence?

3. Does the series impact perceived faculty engagement?

4. Does the series have additional impacts?

5. What improvements to the model do students recommend?

6. How effective was the series implementation? 


\section{RESULTS}

Qualitative analysis was used to identify faculty perceptions regarding the effectiveness and benefits of the Colloquia Series. The data were analyzed using two different strategies. The first strategy was applied to questions one through three and involved keyword-based coding of focus group transcriptions (Vaughn \& Turner, 2015). Utilizing the aforementioned strategy, a thematic analysis of focus group data was conducted, from which two overarching themes emerged: community and engagement. During the second phase of the analysis, data reduction was performed using axial coding. The initial codes and themes were further structured, and only codes that were deemed relevant to the research questions were included (Vaughn \& Turner, 2015).

The new version of the codebook was then used to check all the data on missing codes and record the necessary data. Finally, a selective coding procedure was applied, utilizing SDP as a framework to organize the identified codes.

Questions four through six were analyzed using verbatim text emphasizing rich narratives (Firmin, Bonfils, Luther, Minor, \& Salyers, 2017). Utilizing this method, repetitions, similarities, differences, and transitions were evaluated. This research outlined themes from the six questions posed during the faculty focus group. Out of this discussion, eight themes emerged: collaboration, communication, community, engagement, feedback, instruction, satisfaction, and student interaction.

\section{Keyword Coding}

Results of keyword coding for questions one through three identified several central themes. For question one, "Does the series build academic community in online courses?", responses centered around four key themes:

1) Students: the word "students" was included in each faculty members response.

2) Engage: subthemes ranged from observations that students are not engaged to discussions regarding opportunities for engaging students more fully.

3) Learning: faculty focused on opportunities for increasing student learning through the series.

4) Community: faculty focused on the ways in which they may help to build community. A key subtheme was faculty perceptions regarding the purpose of building community.

The second question, "Does the series impact student perceptions of faculty presence?" resulted in faculty responses which may be categorized into three themes:

1) Students: students were mentioned in $75 \%$ of the responses.

2) Participation: faculty focused on the impact of student participation in the series, discussing perceptions that community would be built more easily if more students were in attendance during sessions.

3) Assessment: Faculty discussed the need for more assessment to increase understanding regarding faculty and student needs.

Question 3, "Does the series impact perceived faculty engagement?" led to responses which focused on three main keywords:

1) Students: students were mentioned in $67 \%$ of the responses.

2) Faculty: the term faculty was mentioned in the majority of the responses.

3) Engage: the term engage was discussed by most faculty present. Sub-themes centered around themes such as level of engagement as a function of faculty role during sessions, perceptions of faculty who did not attend the sessions, and the desire to have information regarding the background of the presenters.

Using the keywords from the responses to the first three questions, a key theme emerged: the need for increased engagement during sessions of the Research Colloquium Series by both students and faculty. Solutions proposed by faculty included a needs assessment, marketing, and the incorporation of feedback regarding session experiences into the faculty's online course(s). 


\section{Verbatim Text Analysis}

Question 4, "Does the series have additional impacts?", was evaluated utilizing verbatim text analysis (see Table 1). Repetitions were assessed and the words marketing and answers were the most frequently utilized. Additionally, critical language pertaining to improvement/opportunities was also frequently observed.

TABLE 1

QUESTION FOUR, VERBATIM TEXT THEMES

\begin{tabular}{|c|c|c|c|}
\hline Word & Length & Faculty Focus Group Notes & Total \\
\hline- & 1 & 20 & 9 \\
\hline $\begin{array}{l}\text { participant } \\
\text { name }\end{array}$ & 5 & 4 & 2 \\
\hline $\begin{array}{l}\text { participant } \\
\text { name }\end{array}$ & 5 & 4 & 2 \\
\hline marketing & 9 & 2 & 2 \\
\hline topics & 6 & 5 & 2 \\
\hline answer & 6 & 1 & 1 \\
\hline around & 6 & 1 & 1 \\
\hline assessment & 10 & 1 & 1 \\
\hline better & 6 & 1 & 1 \\
\hline career & 6 & 2 & 1 \\
\hline course & 6 & 1 & 1 \\
\hline development & 11 & 2 & 1 \\
\hline discussion & 10 & 2 & 1 \\
\hline effect & 6 & 1 & 1 \\
\hline entire & 6 & 2 & 1 \\
\hline etc. & 3 & 1 & 1 \\
\hline faculty & 7 & 4 & 1 \\
\hline feedback & 8 & 1 & 1 \\
\hline follow & 6 & 1 & 1 \\
\hline Goal & 4 & 1 & 1 \\
\hline Goals & 5 & 1 & 1 \\
\hline Good & 4 & 2 & 1 \\
\hline hearing & 7 & 1 & 1 \\
\hline identify & 8 & 1 & 1 \\
\hline improve & 7 & 1 & 1 \\
\hline improved & 8 & 1 & 1 \\
\hline improvements & 12 & 2 & 1 \\
\hline indicates & 9 & 1 & 1 \\
\hline inform & 6 & 1 & 1 \\
\hline initiative & 10 & 2 & 1 \\
\hline innately & 8 & 1 & 1 \\
\hline $\begin{array}{l}\text { participant } \\
\text { name }\end{array}$ & 3 & 4 & 1 \\
\hline Like & 4 & 2 & 1 \\
\hline Main & 4 & 1 & 1 \\
\hline
\end{tabular}




\begin{tabular}{lccc}
\hline Word & Length & Faculty Focus Group Notes & Total \\
\hline Mike & 4 & 2 & 1 \\
moved & 5 & 1 & 1 \\
Need & 4 & 1 & 1 \\
needs & 5 & 1 & 1 \\
networking & 10 & 2 & 1 \\
ongoing & 7 & 1 & 1 \\
opportunities & 13 & 2 & 1 \\
process & 7 & 1 & 1 \\
program & 7 & 1 & 1 \\
relates & 7 & 1 & 1 \\
Room & 4 & 1 & 1 \\
session & 7 & 2 & 1 \\
strategic & 9 & 1 & 1 \\
targeted & 8 & 1 & 1 \\
Will & 4 & 1 & 1 \\
\hline
\end{tabular}

Question 5, "What improvements to the model do students recommend?", was also evaluated utilizing verbatim text analysis. The words research and faculty demonstrated the most repetition (see Table 2). Additionally, words frequently utilized pertained to sharing/communication.

TABLE 2

QUESTION FIVE VERBATIM TEXT THEMES

\begin{tabular}{lccc}
\hline Word & Length & $\begin{array}{l}\text { Faculty Focus } \\
\text { Group Notes }\end{array}$ & Total \\
\hline- & 1 & 20 & 5 \\
research & 8 & 4 & 4 \\
faculty & 7 & 4 & 2 \\
Ask & 3 & 1 & 1 \\
communication & 13 & 1 & 1 \\
current & 7 & 1 & 1 \\
disconnected & 12 & 1 & 1 \\
discuss & 7 & 1 & 1 \\
discussed & 9 & 2 & 1 \\
dissertation & 12 & 2 & 1 \\
Done & 4 & 1 & 1 \\
encourage & 9 & 1 & 1 \\
Felt & 4 & 1 & 1 \\
Get & 3 & 1 & 1 \\
Heard & 5 & 1 & 1 \\
interests & 9 & 1 & 1 \\
participant name & 3 & 4 & 1 \\
participant name & 2 & 2 & 1 \\
May & 3 & 2 & 1 \\
observation & 11 & 1 & 1 \\
\hline
\end{tabular}




\begin{tabular}{lccc}
\hline Word & Length & $\begin{array}{l}\text { Faculty Focus } \\
\text { Group Notes }\end{array}$ & Total \\
\hline opportunities & 13 & 2 & 1 \\
perhaps & 7 & 1 & 1 \\
present & 7 & 1 & 1 \\
semantics & 9 & 1 & 1 \\
Share & 5 & 1 & 1 \\
students & 8 & 2 & 1 \\
Tense & 5 & 1 & 1 \\
together & 8 & 1 & 1 \\
Want & 4 & 2 & 1 \\
Year & 4 & 1 & 1 \\
\hline
\end{tabular}

Responses to the final focus group question, Question 6, "How effective was the series implementation?" revealed an emphasis on marketing and topics, based on an analysis of repetitions (see Table 3). Additional words frequently observed related to exchange-of-information.

TABLE 3

QUESTION SIX VERBATIM TEXT THEMES

\begin{tabular}{lccc}
\hline Word & Length & $\begin{array}{c}\text { Faculty Focus } \\
\text { Group Notes }\end{array}$ & Total \\
\hline- & 1 & 20 & 9 \\
participant name & 5 & 4 & 2 \\
participant name & 5 & 4 & 2 \\
marketing & 9 & 2 & 2 \\
topics & 6 & 5 & 2 \\
answer & 6 & 1 & 1 \\
around & 6 & 1 & 1 \\
assessment & 10 & 1 & 1 \\
better & 6 & 1 & 1 \\
career & 6 & 2 & 1 \\
course & 6 & 1 & 1 \\
development & 11 & 2 & 1 \\
discussion & 10 & 2 & 1 \\
effect & 6 & 1 & 1 \\
entire & 6 & 2 & 1 \\
etc. & 3 & 1 & 1 \\
faculty & 7 & 4 & 1 \\
feedback & 8 & 1 & 1 \\
follow & 6 & 1 & 1 \\
Goal & 4 & 1 & 1 \\
Goals & 5 & 1 & 1 \\
Good & 4 & 2 & 1 \\
hearing & 7 & 1 & 1 \\
identify & 8 & 1 & 1 \\
\hline & & & \\
\hline
\end{tabular}




\begin{tabular}{lccc}
\hline Word & $\begin{array}{c}\text { Length } \\
\text { improve }\end{array}$ & $\begin{array}{l}\text { Faculty Focus } \\
\text { Group Notes }\end{array}$ & Total \\
improved & 7 & 1 & 1 \\
improvements & 8 & 1 & 1 \\
indicates & 12 & 2 & 1 \\
inform & 9 & 1 & 1 \\
initiative & 6 & 1 & 1 \\
innately & 10 & 2 & 1 \\
participant name & 8 & 1 & 1 \\
Like & 3 & 4 & 1 \\
Main & 4 & 2 & 1 \\
Mike & 4 & 1 & 1 \\
moved & 4 & 2 & 1 \\
Need & 5 & 1 & 1 \\
needs & 4 & 1 & 1 \\
networking & 5 & 1 & 1 \\
ongoing & 10 & 2 & 1 \\
opportunities & 7 & 1 & 1 \\
process & 13 & 2 & 1 \\
program & 7 & 1 & 1 \\
relates & 7 & 1 & 1 \\
Room & 7 & 1 & 1 \\
session & 4 & 1 & 1 \\
strategic & 7 & 2 & 1 \\
targeted & 9 & 1 & 1 \\
participant name & 8 & 1 & 1 \\
\hline
\end{tabular}

Repeated sentiments pertaining to communication, marketing, goals/expectations, planning, strategy, and classroom impact emerged from this analysis. Similarities of sentiment can be categorized as strategy/planning suggestions, confusion/expectations statements, experienced classroom impact, alignment/needs assessment, marketing concerns, opportunities for improvement, and feeling disconnected. Faculty shared the desire for more discussion and improved communication regarding the Research Colloquium Series and its aims. Overall, the themes taken from both of the qualitative analyses employed fit in a several broad categories.

\section{Thematic Categories}

The first category was opportunities for improvement pertaining to marketing and communication regarding the Research Colloquium Series to faculty. Faculty shared perceptions regarding opportunities for improvement in communication, marketing, discussion, sharing, and the communication of expectations regarding the series. The second category was goals. Faculty shared their views regarding the benefits of conducting an assessment of student and faculty needs and utilizing the results of this assessment to inform series goals. Further, faculty shared views regarding planning and goal development to best provide engagement opportunities with relevance to research to students. The final category was classroom impact. Faculty shared perceptions regarding the potential for the series to impact engagement. Additionally, faculty shared experience regarding discussions based on the series which continued in the online classroom, demonstrating the potential for this series to engage both students and faculty in continued dialogue regarding research. 


\section{DISCUSSION}

Findings of this analysis indicate that the Research Colloquium Series may further impact faculty engagement following a reassessment of the effectiveness of the positioning and marketing of the series to program faculty. Views shared regarding the potential to reposition the series are very valuable and can be utilized to inform the announcement of future sessions in the series. One important first step is to engage with administrators to clarify faculty expectations regarding the series, after which point expectations can be shared with faculty. Expectations will involve two key aspects. The first aspect pertains to expectations for the manner in which the series is intended to benefit faculty. This will focus on opportunities to connect with peers, students, and administrators, as well as the opportunity to share research and engage as a consumer of the research of peers. The second aspect relates to expectations for the manner in which faculty may contribute to the series. This will focus on opportunities for faculty to present their research or to present on research-related topics that are of interest to doctoral students. An emphasis will be placed on demonstrating value for faculty area of expertise and empowering faculty to share their experience with peers, administrators, and students. A second key finding pertained to goals.

Faculty shared the benefits they perceived in assessing the needs of students and faculty. Faculty feedback indicated that clarity regarding the aims of the Research Colloquium Series were lacking in clarity. Themes regarding needs and benefits of students as compared to the needs and benefits of faculty were discussed in terms of their impact on topic selection and format of sessions in the colloquium series. Benefits to both students and faculty can be realized simultaneously through careful design and the involvement of faculty. The willingness of faculty to engage in the focus group, share their perceptions and feedback in a transparent manner, and express an eagerness to inform future iterations of the series demonstrates a tremendous level of community within the program. This group possesses intrinsic motivation to empower and engage with one another, and to empower and engage students that is consistent with Self Determination Theory (Jansen in de Wal, van den Beemt, Martens, \& den Brok,2020; Ryan \& Deci, 2000; Stupnisky, BrckaLorenz, Yuhas, \& Guay,2018; Stupnisky, Hall, Daniels, \& Mensah, 2017). This motivation plays a powerful role in the goal directed nature of the group as a whole. The final theme, classroom impact, also indicates the potential for the Research Colloquium Series to build increased levels of community among faculty and students.

These findings provide support for Self Determination Theory, as a notable level of engagement, intrinsic motivation and empowerment was evident. Daly (2011) indicated that faculty learning and growth can be enhanced by including autonomous self-directed activities in the faculty learning community. There should also be opportunities to build competence and create collaborations between departments. These factors support faculty professional development opportunities in future colloquia. Also, as Jansen in de Wal, van den Beemt, Martens, \& den Brok (2020) found, that there are important relationships among professional learning, teachers' experience of job resources, motivation, and need satisfaction. This provides more support for focusing on the content of faculty colloquia.

Faculty shared experiences involving discussions regarding colloquium topics in the online classroom. Further, faculty shared suggestions for improving the connections between content discussed during sessions in the series and content presented in formal coursework. Future research may involve the evaluation of program curriculum with the aim of identifying key courses during which colloquium sessions would fit well. Additional area of focus include the possibility of offering sessions which are more targeted in nature to a smaller group of students and faculty. For instance, a colloquium session could be developed for students and faculty in the first 4 doctoral courses. This session might focus on areas of importance for new doctoral students who have not yet begun to focus on research in a formal manner. Conducting a session with a smaller group would also allow for the possibility of increased participation by students and faculty alike, which may lead to increased engagement.

This study focused on the preliminary evaluation of a recently implemented Research Colloquium Series offered to doctoral students and faculty in a program offered through the online campus of a midsized university. Pertinent literature was utilized to inform the selection of questions posed during a focus group attended by 11 faculty members teaching in the program. Themes centering around 
opportunities for improvement, goals of the series and their impact on direction, and classroom impact emerged. Future work will focus on the exploration of variations to the main model presented to more effectively assess the impact of the series on faculty and their level of engagement.

\section{REFERENCES}

Beachboard, M., Beachboard, J., Li, W., \& Adkison, S. (2011). Cohorts and relatedness: SelfDetermination Theory as an explanation of how learning communities affect educational outcomes. Research in Higher Education, 52(8), 853-874.

Benton, S., \& Li, D. (2015). Professional development for online adjunct faculty: The Chair's role. The Department Chair, 26(1), 1-4.

Bolliger, D. U., \& Wasilik, O. (2009). Factors influencing faculty satisfaction with online teaching and learning in higher education. Distance Education, 30(1), 103-116.

Borrero, N., \& Reed, J. (2016). A case for community partnership and professional development: A nineweek service-learning seminar for faculty. Partnerships: A Journal of Service Learning and Civic Engagement, 7(1), 27-53.

Byrne, Z., Peters, J., \& Weston, J. (2016). The struggle with employee engagement: Measures and construct clarification using five samples. Journal of Applied Psychology, 101(9), 1201-1227.

Daly, C. J. (2011). Faculty Learning Communities: Addressing the professional development needs of faculty and the learning needs of students. Currents in Teaching \& Learning, 4(1), 3.

Deci, E. L., \& Ryan, R. M. (2000). The "what" and "why" of goal pursuits: Human needs and the selfdetermination of behavior. Psychological Inquiry, 11, 227-268.

Deligero, J., \& Laguador, J. (2014). Work engagement among employees and its relationships with work units' performance of a higher education institution. International Journal of Management Services, 3(12), 909-917.

Dolan, V. (2011). The isolation of online adjunct faculty and its impact on their performance. International Review of Research in Open and Distance Learning, 12(2), 62-79.

Firmin, R.L, Bonfils, K.A., Luther, L., Minor, K.S, Salyers, M.P. (2017). Using text-analysis computer software and thematic analysis on the same qualitative data: A case example. Qualitative Psychology, 4(3), 201-210.

Golden, J. E. (2016). Supporting online faculty through communities of practice: Finding the faculty voice. Innovations in Education \& Teaching International, 53(1), 84-93.

Hakeem, I., \& Gulzar, S. (2015). Employee engagement: An empirical study of higher education sector in Kashmir. Abhinav International Monthly Refereed Journal of Research in Management \& Technology, 4(4), 20-27.

Henrie, C. R., Halverson, L. R., \& Graham, C. R. (2015). Measuring student engagement in technologymediated learning: A review. Computers \& Education, 90, 36-53.

Huang, X., \& Hsiao, E-L. (2012). Synchronous and asynchronous communication in an online environment: Faculty experiences and perceptions. Quarterly Review of Distance Education, 13(1), 15-30.

Jackson, D., Stebleton, M., \& Laanan, F. (2013). The experience of community college faculty involved in a learning community program. Community College Review, 4l(1), 3-19.

Jansen in de Wal, J., van den Beemt, A., Martens, R. L., \& den Brok, P. J. (2020). The relationship between job demands, job resources and teachers' professional learning: Is it explained by selfdetermination theory? Studies in Continuing Education, 42(1), 17-39. https://doiorg.ezp.waldenulibrary.org/10.1080/0158037X.2018.1520697

Khalid, F., Joyes, G., Ellison, L., \& Daud, M. Y. (2014). Factors influencing teachers' level of participation in online communities. International Education Studies, 7(13), 23-32.

Kreie, J., Johnson, S., \& Lebsock, M. (2017). Course design and technology for synchronous interaction in an online course. Information Systems Education Journal, 15(5), 60-67. 
Loversidge, J., \& Demb, A. (2015). Faculty perceptions of key factors in interprofessional education. Journal of Interprofessional Care, 29(4), 298-304.

Lowenthal, P. R., Snelson, C., \& Dunlap, J. C. (2017). Live synchronous web meetings in asynchronous online courses: Reconceptualizing virtual office hours. Online Learning, 21(4), 177-194.

Martinek, D. (2019). The consequences of job-related pressure for self-determined teaching. Social Psychology of Education, 22(1), 133-148.

Meixner, C., Kruck, S., \& Madden, L. (2010). Inclusion of part-time faculty for the benefit of faculty and students. College Teaching, 58, 141-147.

Moskal, P., Thompson, K., \& Futch, L. (2015). Enrollment, engagement, and satisfaction in the Blend Kit Faculty Development Open Online Course. Online Learning, 19(4), 100-113.

Mueller, B., Mandernach, B. J., \& Sanderson, K. (2013). Adjunct versus full-time faculty: Comparison of student outcomes in the online classroom. Journal of Online Learning and Teaching, 9(3), 341.

Park, Y. J., \& Bonk, C. J. (2007). Is online life a breeze? A case study for promoting synchronous learning in a blended graduate course. MERLOT Journal of Online Learning and Teaching, 3(3), 307-323.

Renner, J. (2017). Engaging TBR faculty in online research communities and emerging technologies. Journal of Learning in Higher Education, 13(1), 33-44.

Ryan, R. M., \& Deci, E. L. (2000). Self-determination theory and the facilitation of intrinsic motivation, social development, and well-being. American Psychologist, 55, 68-78. Journal of Learning in Higher Education, 13(1), 33-40.

Smith, W. (2015). Relational dimensions of virtual social work education: Mentoring faculty in a webbased learning environment. Clinical Social Work Journal, 43, 236-245.

Stupnisky, R. H., BrckaLorenz, A., Yuhas, B., \& Guay, F. (2018). Faculty members' motivation for teaching and best practices: Testing a model based on self-determination theory across institution types. Contemporary Educational Psychology, 53, 15-26. https://doiorg.ezp.waldenulibrary.org/10.1016/j.cedpsych.2018.01.004

Stupnisky, R. H., Hall, N. C., Daniels, L. M., \& Mensah, E. (2017). Testing a model of pre-tenure faculty members' teaching and research success: Motivation as a mediator of balance, expectations, and collegiality. Journal of Higher Education, 88(3), 376-400. https://doiorg.ezp.waldenulibrary.org/10.1080/00221546.2016.1272317

Surak, S., \& Pope, A. (2016). Engaging the educators: Facilitating civic engagement through faculty development. Journal of Higher Education Outreach, 20(3), 140-164.

van der Berg, B., Bakker, A., \& Cate, T. (2013). Key factors in work engagement and job motivation of teaching faculty at a university medical center. Perspectives in Medical Education, 2, 264-275.

Vaughn, P., \& Turner, C. (2015). Decoding via coding: Analyzing qualitative text data through thematic coding and survey methodologies. Journal of Library Administration, 56(1), 41-51.

Vines, A. (2010). Productive horizontal learning: A study of law students' engagement in informal peer colloquia. International Journal of the Scholarship of Teaching and Learning, 4(1), 1-20.

Webb, A., Wong, T., \& Hubball, H. (2013). Professional development for adjunct teaching faculty in a research-intensive university: Engagement in scholarly approaches to teaching and learning. International Journal of Teaching and Learning in Higher Education, 25(7), 231-238. 


\section{APPENDIX A}

\section{RESEARCH COLLOQUIUM SERIES MODEL}

\section{Overview}

The Research Colloquium Series Model provides faculty teaching for the program at a midsize university's online campus the opportunity to present planned, ongoing and/or complete research projects in which they are involved during synchronous program-wide meetings. Additionally, faculty may present on topics proposed by doctoral students with relevance to the research process. Faculty and doctoral students come together outside of the online course room and meet via Zoom web conferencing software. Meetings are scheduled once per semester and the duration of each meeting is 1 hour.

\section{Aims}

1. Engage faculty and students outside of the online course room in meaningful ways, thereby contributing to the development of community.

2. Maximize meaningful interactions in a synchronous environment, thereby contributing to student and faculty engagement.

3. Provide faculty and students with a forum to discuss research.

4. Provide faculty with opportunities to mentor students throughout the research process. 